\title{
Correction to: From Images to Reports
}

\section{Correction to: Chapter 9 in: D. Rosenthal, O. Pianykh, Efficient Radiology, https://doi.org/10.1007/978-3-030-53610-7_9}

The original version of Chapter 9 was inadvertently published with an incorrect year in the first line of Section 9.1. It is corrected as "1895". 